\title{
Cardiopulmonary complications induced by Iranian Mesobuthus eupeus scorpion venom in anesthetized rabbits
}

\section{Zayerzadeh E (1), Koohi MK (1), Zare Mirakabadi A (2), Purkabireh M (3), Kassaaian SE (4), Rabbani SH (4), Sotoudeh Anvari M (4), Boroumand MA (4), Sadeghian S (4)}

(1) Department of Toxicology, Faculty of Veterinary Medicine, Tehran University, Tehran, Iran; (2) Department of Venomous Animals and Antivenom Production, Razi Vaccine and Serum Research Institute, Karaj, Iran; (3) Department of Biochemistry, Faculty of Veterinary Medicine, Tehran University, Tehran, Iran; (4) Tehran University Heart Center, Tehran University of Medical Sciences, Tehran, Iran.

ABSTRACT: Scorpion envenomation is a life-threatening condition, especially in children and elderly individuals affected by respiratory and cardiovascular diseases. In this study, the toxic effects of median lethal dose (LD50) injections of Mesobuthus eupeus (Me) venom on the heart and lungs of anesthetized rabbits were investigated. Six rabbits were selected and alterations in their electrocardiogram, heart rate, respiration and blood pressure before and after venom injection were recorded. Cardiac troponin T (cTnT), creatinine kinase muscle-brain fraction (CK-MB) and lactate dehydrogenase (LDH) were measured at 0,1 and 3 hours after envenomation and pathology studies were carried out postmortem. All the animals showed signs and symptoms of envenomation within 40 minutes and died 3 to 3.5 hours after venom injection. Pathology studies revealed alveolar edema in $100 \%$ of the rabbits and myocardial infarction in $16 \%$. The main histopathological changes were myocytolysis, coagulation necrosis, focal hemorrhage, thrombus formation both in myocardium and on endocardial surfaces as well as inflammatory infiltrates in the heart and hemorrhage, vascular thrombus and interstitial inflammation in the lungs. ECG monitoring of rabbits showed ST elevation, ST depression and inverted $T$ and $Q$ waves. In addition, although cTnT levels increased in $16 \%$ of the animals and serum LDH was also augmented, none of these changes was statistically significant. The enzyme CK-MB also did not show any change after $M e$ venom injection. In conclusion, the results of this study showed that Me venom killed animals in less than 3.5 hours through severe pulmonary damage and it appears that the deaths could not be attributed to cardiovascular lesions. Therefore, Me venom effects on the lungs are so important that they appear to be independent of heart damage.

KEY WORDS: Mesobuthus eupeus, scorpion experimental envenomation, histopathological changes, electrocardiogram changes, troponin.

CONFLICTS OF INTEREST: There is no conflict.

\section{CORRESPONDENCE TO:}

ABBAS ZARE MIRAKABADI, Department of Venomous Animals and Antivenom Production, Razi Vaccine and Serum Research Institute, Karaj, Iran. Phone: +98 261 4502865. Email: abbas.zare8@gmail.com. 


\section{INTRODUCTION}

Scorpion envenomation is a life-threatening condition, especially in children and older individuals who suffer from respiratory and cardiovascular disease (1). Mesobuthus eupeus is one of the major scorpions in Iran and its stings constitute a public health problem. The majority of stings that occur in Iran are attributed to the Buthidae family, which includes Mesobuthus eupeus, Androctonus crassicauda, Odontobuthus odonturus and Apistobuthus pertigus (2). In addition, Mesobuthus eupeus shows high geographic distribution in Turkey, Iraq, Turkestan, Afghanistan and Pakistan. Therefore, Mesobuthus eupeus is known as a central Asian scorpion (3). Radmanesh (2) showed that $45 \%$ of all cases of scorpion stings were due to Mesobuthus eupeus in Iran.

The venom from Buthidae family scorpions produces myocarditis, sialorrhoea, tachycardia, tachypnea and respiratory distress (4-8). Other studies reported heart failure, cardiac arrhythmias, acute pulmonary edema and respiratory failure after severe Androctonus australis envenomation (7, 9, 10). Mesobuthus tamulus envenomation presents acute myocarditis, dysrhythmia, myocardial ischemia, hypotension or hypertension and pulmonary edema (11). Following a Mesobuthus eupeus sting, victims have presented severe pain, hyperemia, edema, thirst, dry mouth, hypotension, nausea, hypertension, elevated bronchial secretion, difficulty in breathing, tachycardia and cyanosis (12). There are controversial views on the mechanism of respiratory complications in scorpion envenomation $(13,14)$. However a high-molecular-weight (100 kDa) toxin (T3) exhibiting toxicity in cardiopulmonary parameters was isolated from Mesobuthus tamulus venom, and was denominated "pulmonary edema-producing toxin (PoTx)" which was identified as the principle toxin in the manifestation of pulmonary edema seen after Mesobuthus tamulus envenomation (15). To the best of our knowledge, no report has been published regarding the cardiorespiratory effects of Iranian Mesobuthus eupeus scorpion venom. Therefore, the present study was undertaken to investigate cardiovascular and respiratory effects in anesthetized rabbits following Mesobuthus eupeus envenomation. 


\section{MATERIALS AND METHODS}

\section{Venom}

Mesobuthus eupeus venom was obtained by electric shock at the scorpion telson in the Department of Venomous Animals and Antivenom Production, Razi Vaccine and Serum Research Institute of Iran. It was lyophilized and stored at $4^{\circ} \mathrm{C}$ until use.

\section{Experimental Protocol}

Six male New Zealand white rabbits with an average weight of $2 \mathrm{~kg}$ were used in this study. All animals were housed under conditions of controlled light (12-hour-light 12hour-dark cycle), temperature $\left(24 \pm 1^{\circ} \mathrm{C}\right)$ and humidity $(55 \pm 5 \%)$, with standard diet and water available ad libitum. All animals were injected with $50 \mathrm{mg} / \mathrm{kg}$ ketamine and $5 \mathrm{mg} / \mathrm{kg}$ xylazine (intramuscular to induce anesthesia). All animals were kept in compliance with the recommendations of the Animal Care Committee of the Tehran University based on the Guide for Care and Use of Laboratory Animals (US NIH publication 86-23, revised 1985). All animals were subcutaneously injected with a lethal dose $(4.5 \mathrm{mg} / \mathrm{kg}$ of body weight) of Me venom.

\section{Electrocardiogram, Blood Pressure and Arterial Oxygen Saturation Recording}

Electrocardiogram was recorded at regular intervals using 12 electrocardiographic leads (Cardimax FX-2111®, Fukudadenshi, Japan). Blood pressure was measured until death using the neonatal blood pressure cuff from a Spacelabs medical device (Spacelabs Medical Incorporation, USA). Arterial oxygen saturation was measured using a Spacelabs sensor.

\section{Assay of Myocardial Markers}

Troponin $\mathrm{T}(\mathrm{TnT})$ was measured using an electrochemiluminescence immunoassay (Elecsys $2010 \circledR$ analyzer and Troponin T STAT® kit, Roche, Germany) according to the manufacturer's instructions. Lactate dehydrogenase (LDH) and creatinine kinasemuscle brain (CK-MB) were assayed in the sera using the electrochemiluminescence immunoassay (Elecsys 2010® analyzer and CK-MB STAT $®$ kit, Roche, Germany) according to the manufacturer's instructions. The enzyme values were expressed in international units $(\mu \mathrm{g} / \mathrm{L})$. 


\section{Histological Analysis}

After the animals died the heart and lungs were removed carefully and immersed in $10 \%$ buffered formalin at room temperature and then sectioned transversely into 3-4 $\mu \mathrm{m}$ slices. Specimens were dehydrated in a graded series of alcohol and xylene and embedded in paraffin. Multiple slices were made and stained by hematoxilin and eosin stains. Sections were viewed and photographed using a Nikon E200® light microscope (Japan).

\section{Statistical Analysis}

All results were expressed as mean $\pm S D$. The statistical significance of differences among groups was analyzed by the Student's $t$-test. Data were considered statistically significant if $p$-values were $<0.05$.

\section{RESULTS}

\section{Histopathological Evaluation}

Histopathological evaluation of the heart showed extensive coagulation necrosis in one rabbit, myocytolysis in two animals, focal hemorrhage and thrombus formation in myocardium and endocardial surfaces in two rabbits and lymphomononuclear inflammatory infiltration in three rabbits. Evaluation of the lungs showed alveolar edema in all animals, thrombus formation in two rabbits, hemorrhage in three rabbits, vascular congestion in five rabbits and lymphomononuclear interstitial inflammation in three rabbits (Figure 1). 


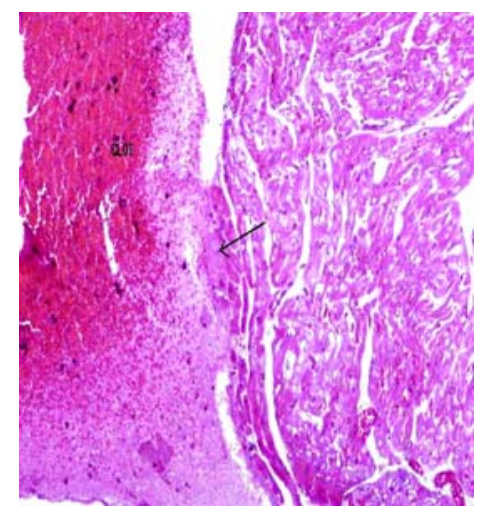

A

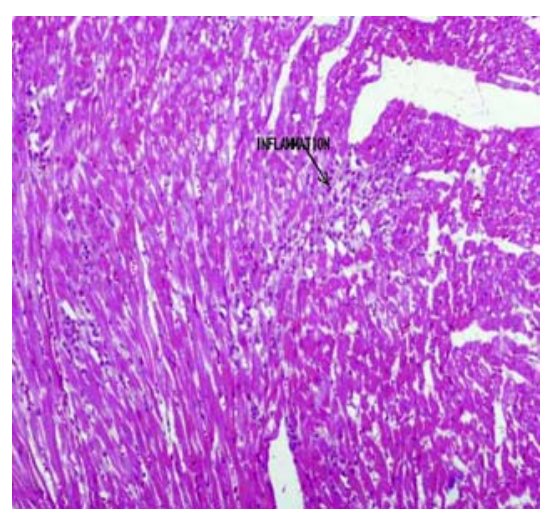

C

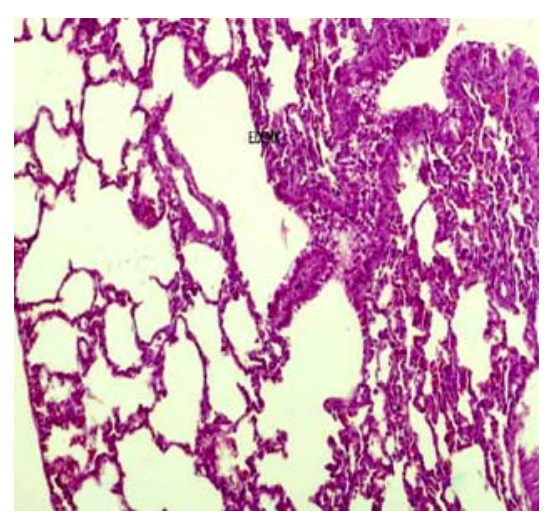

E

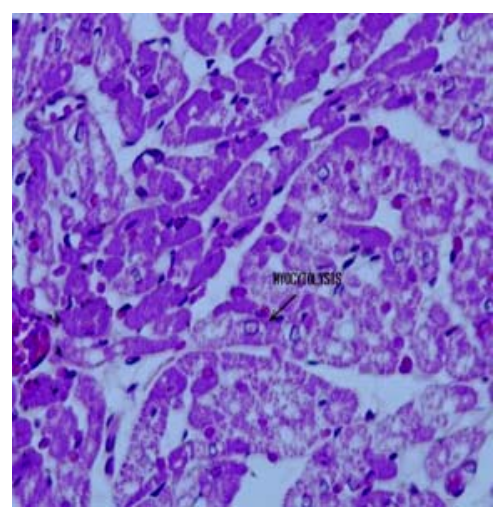

B

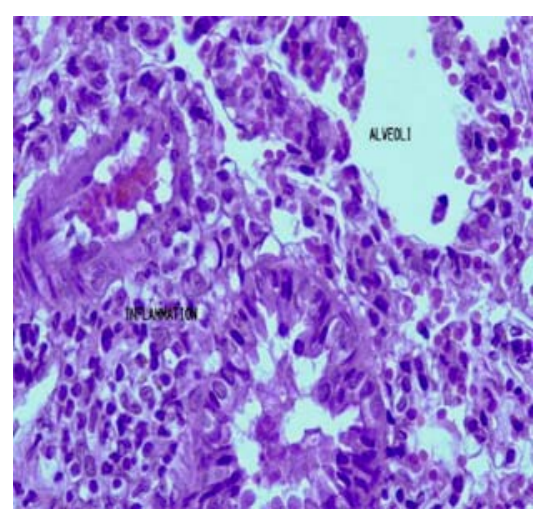

D

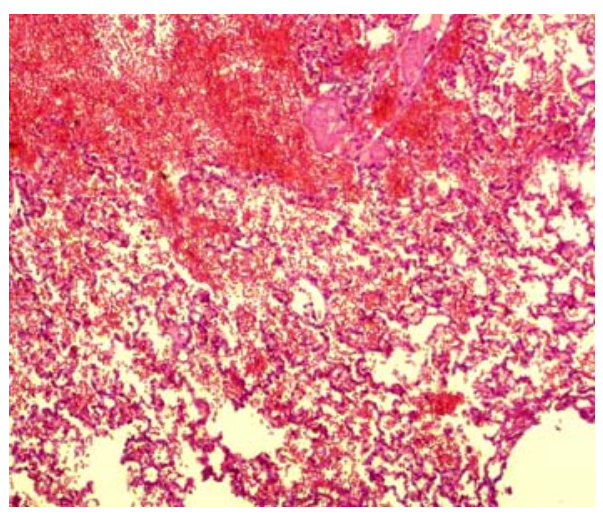

$\mathbf{F}$

Figure 1. Histopathological changes of heart (A, B, C) and lung (D, E, F) tissue induced by Mesobuthus eupeus venom ( $90 \mu \mathrm{g} / 20 \mathrm{~g}$ body weight). From 3 to 3.5 hours after evenomation, (A) thrombus on the endocardium, (B) myocytolisis and (C) lymphomononuclear inflammatory infiltrate on the myocardium are present. Three hours after envenomation, (D) lymphomononuclear inflammatory infiltrate in the lung, (E) pulmonary edema and (F) pulmonary hemorrhage were present. 


\section{Tissue Necrosis Marker Assays after Envenomation}

Tissue necrosis marker assays showed a non-significant increase in the level of TnT activities in the serum of all envenomated rabbits. However, the TnT level in one rabbit that showed considerable ECG alterations (infarct-like patterns) and severe histopathological alterations (coagulation necrosis, myocytolysis) was considerably higher than in the others. Serum LDH displayed non-significant increase after venom injection. CK-MB measurement did not show significant changes (Table 1).

Table 1. Tissue necrosis marker changes in anesthetized rabbits before and one and three hours after Me venom injection

\begin{tabular}{l|c|c|c|c}
\hline \multicolumn{5}{c}{ Mean \pm SEM } \\
\hline TnT & Baseline & After 1 hour & After 3 hours & p value \\
\hline CK-MB & 0 & $0.09 \pm 0.24$ & $0.22 \pm 0.54$ & NS \\
\hline LDH & $1.04 \pm 0.08$ & $1.05 \pm 0.03$ & $0.91 \pm 0.09$ & NS \\
\hline
\end{tabular}

Baseline: before venom injection; TnT: troponin T, CK-MB: creatinine kinase muscle-brain; LDH: lactate dehydrogenase; NS: not significant $(p<0.05)$.

\section{Effect of Venom on ECG, Blood Pressure, Heart Rate, Respiratory Rate and Arterial Oxygen Saturation}

In one rabbit that showed higher TnT elevation in the serum and histopathological complications, as compared to other rabbits, the ECG showed an infarct-like pattern (ST elevation in I, II and AVF, ST depression in AVF, V1, V2 and V3, Q waves in I, II and AVF) at 20, 30 and 180 minutes after Me venom injection, respectively (Figure 2). The electrocardiograph of another rabbit showed inverted $T$ waves in I, II, AVL, V3, V4, V5 and V6; ST depression in I, II, AVL, V1, V2, V3, V4, V5 and V6; ST elevation in AVR and $\mathrm{V} 1$ at 180 minutes after $M e$ venom injection (Figure 3). This rabbit did not show significant $\mathrm{TnT}$ elevation. Electrocardiogram in the other rabbits did not show any changes. By 40-60 minutes after venom injection there were severe respiratory alterations such as respiratory distress, apnea, open-mouth respiration and finally respiratory arrest. Blood pressure progressively decreased until rabbits died at $180 \pm 30$ minutes. Furthermore, the injection of Me venom caused no significant decrease in heart rate until death (Table 2). 
Zayerzadeh E et al. Cardiopulmonary complications induced by Iranian Mesobuthus eupeus scorpion venom in anesthetized rabbits. J Venom Anim Toxins incl Trop Dis. 2010;16(1):52

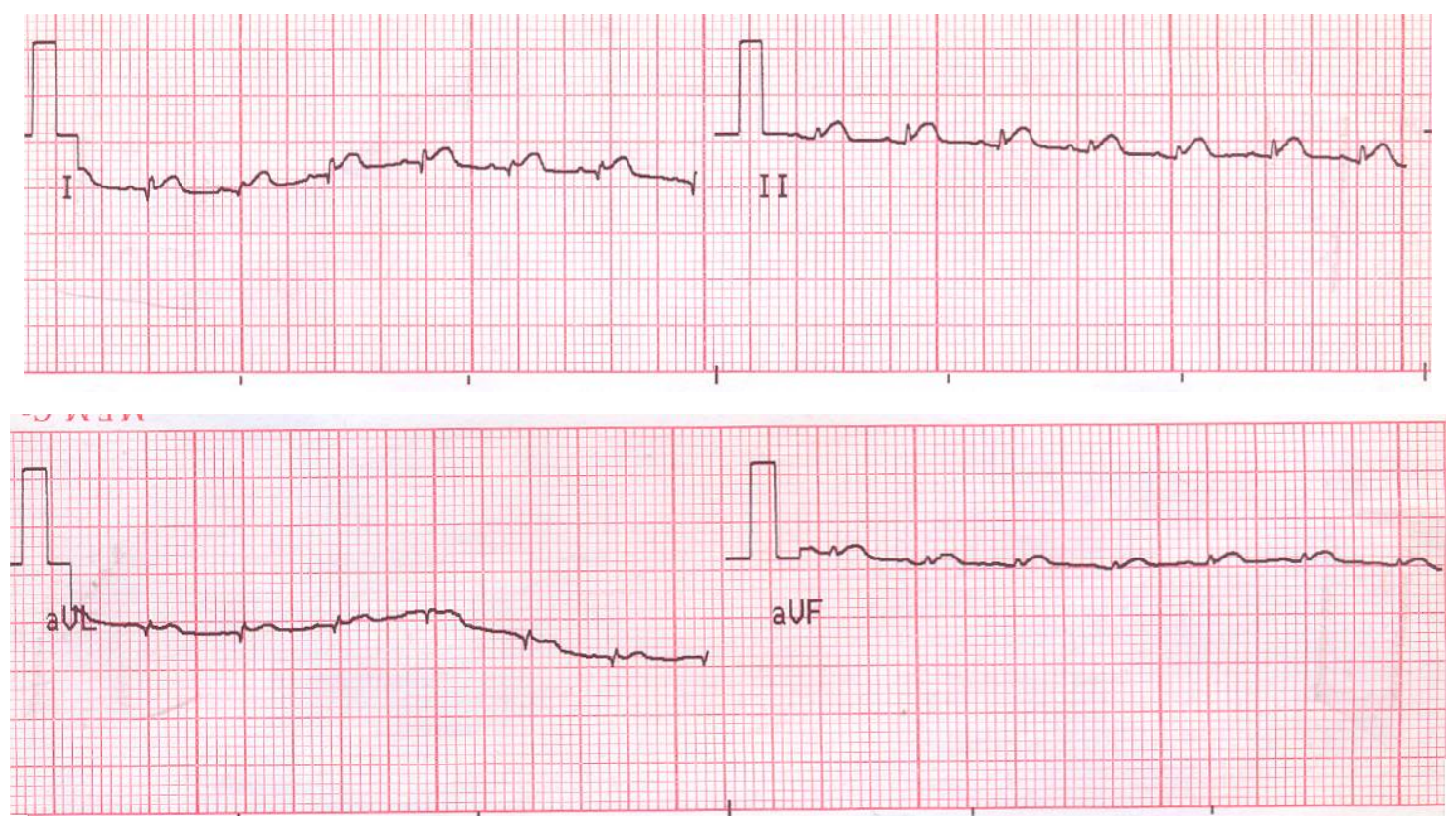

A

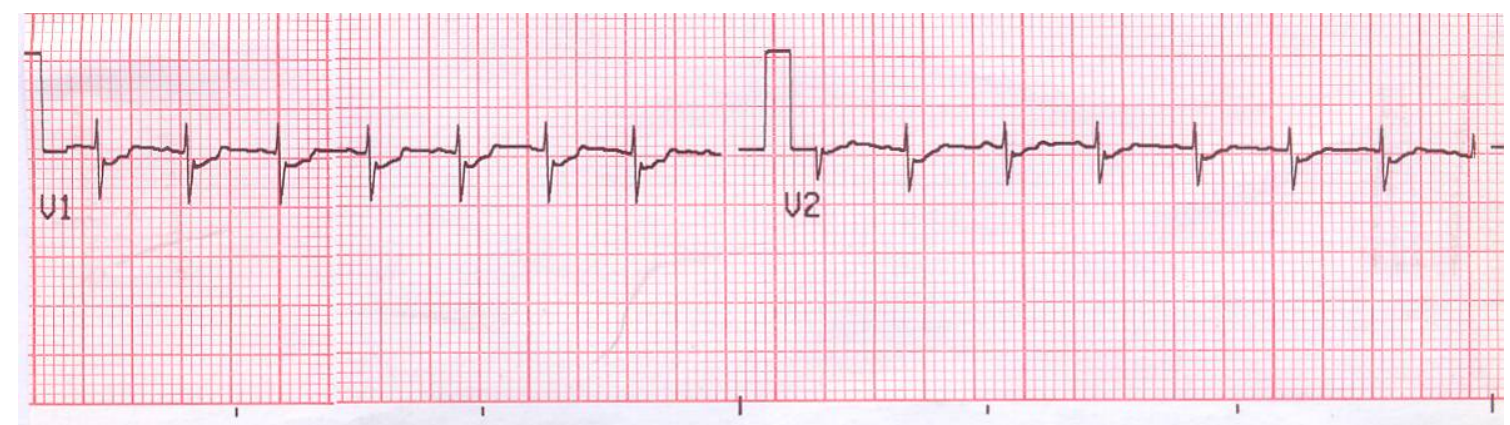

•

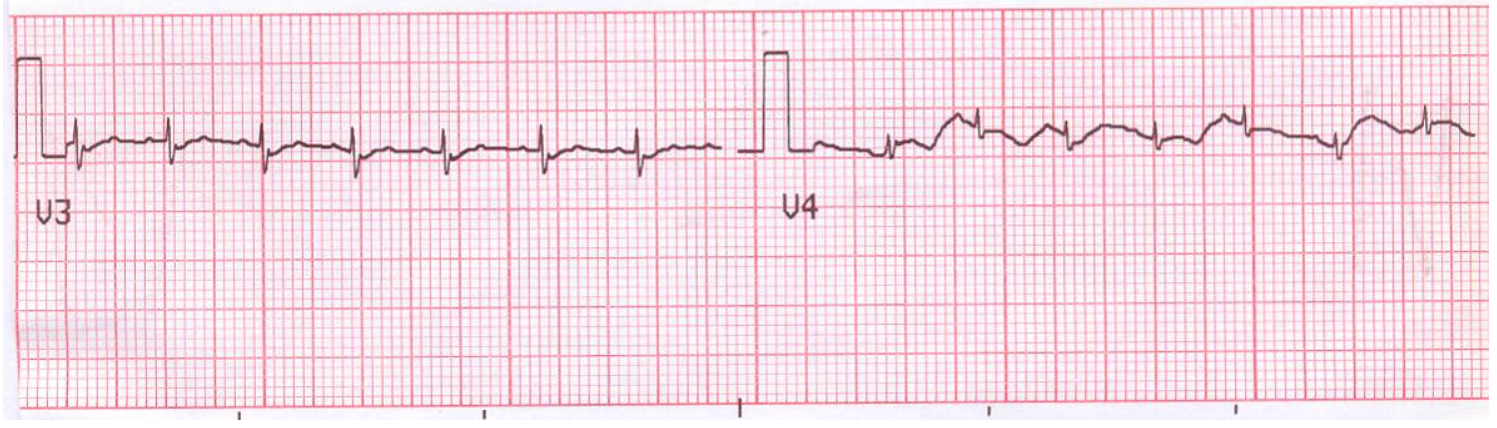


Zayerzadeh E et al. Cardiopulmonary complications induced by Iranian Mesobuthus eupeus scorpion venom in anesthetized rabbits. J Venom Anim Toxins incl Trop Dis. 2010;16(1):53
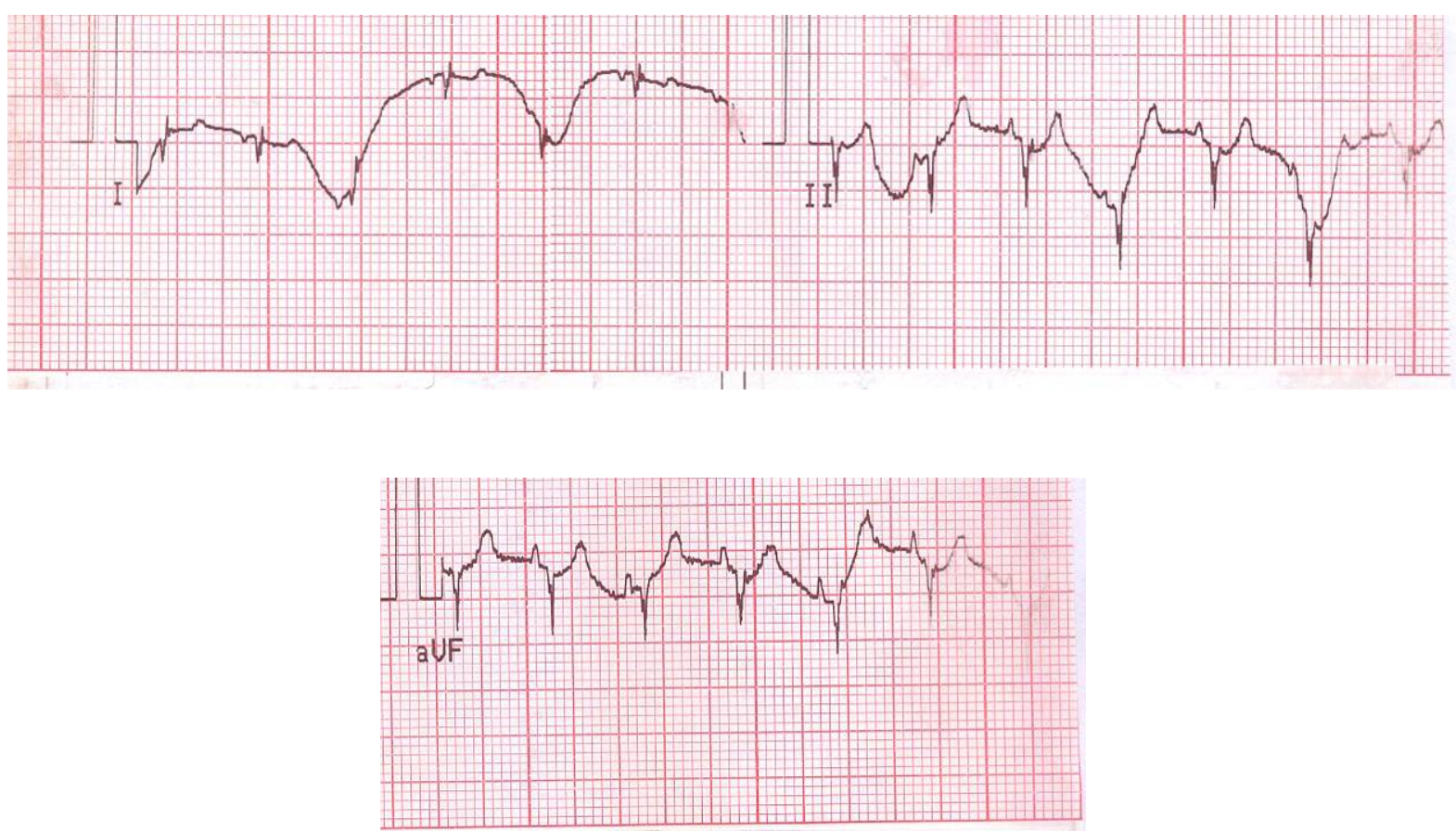

C

Figure 2. (A) ST elevation in I, II and AVF, (B) ST depression in V1, V2 and V3, (C) $\mathrm{Q}$ waves in I, II and AVF at 20, 30 and 180 minutes after Me venom injection, respectively. 
Zayerzadeh E et al. Cardiopulmonary complications induced by Iranian Mesobuthus eupeus scorpion venom in anesthetized rabbits. J Venom Anim Toxins incl Trop Dis. 2010;16(1):54

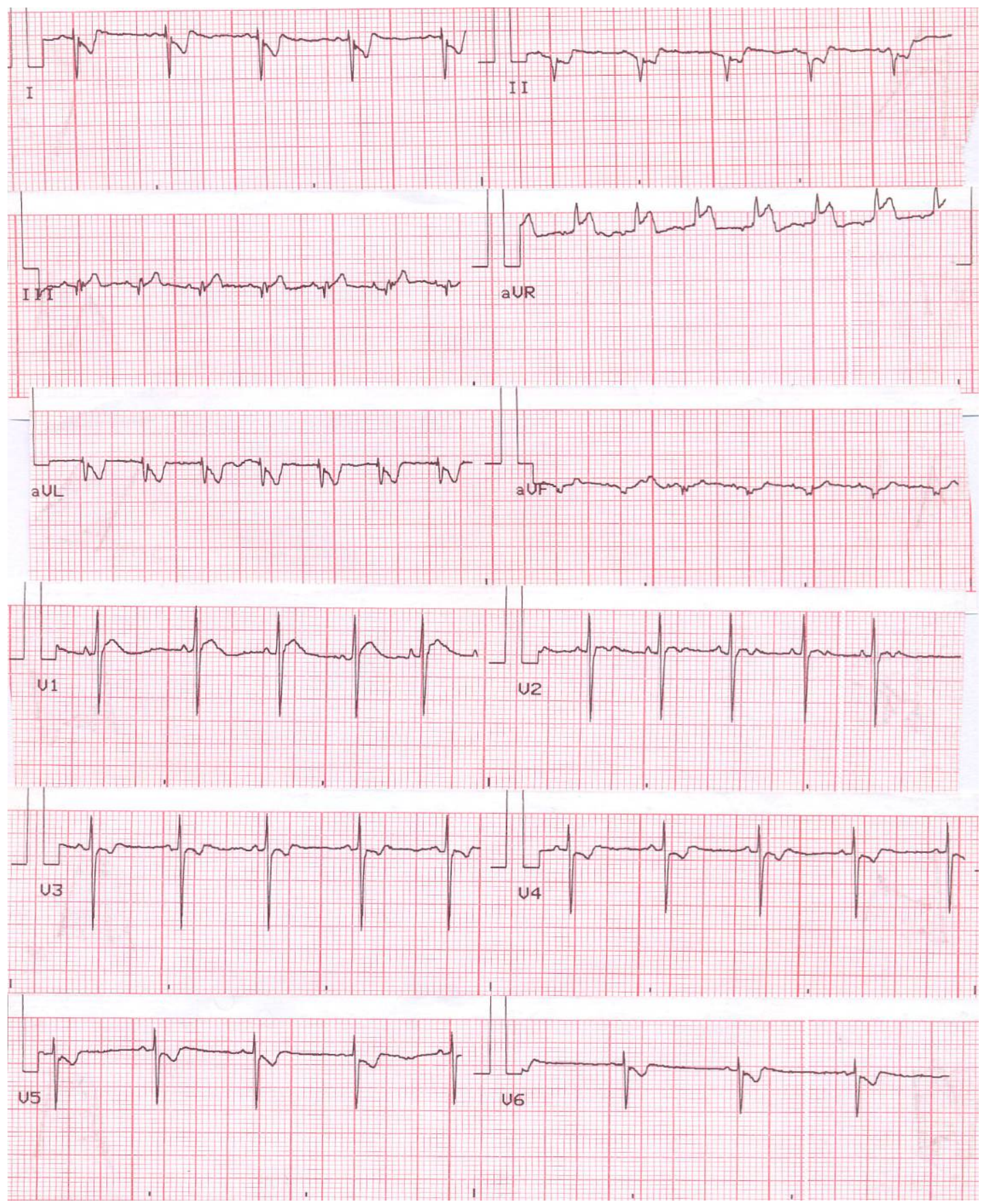

Figure 3. Inverted T waves in I, II, AVL, V3, V4, V5 and V6; ST depression in I, II, AVL, V1, V2, V3, V4, V5 and V6; ST elevation in AVR and V1 at 180 minutes after Me venom injection. 
Table 2. Heart rate, blood pressure, respiratory rate and saturation changes in anesthetized rabbits after Me venom injection

\begin{tabular}{ccccc}
\hline & \multicolumn{5}{c}{ Mean \pm SEM } \\
\hline BR & $187 \pm 16$ & After $\mathbf{1}$ hour & After 3 hours & p value \\
\hline MABP & $8.1 \pm 0.1$ & $149 \pm 14$ & $146 \pm 19$ & NS \\
\hline RR & $50 \pm 3$ & $6.1 \pm 0.42$ & $3.7 \pm 0.5$ & $\mathrm{~S}$ \\
\hline $\mathbf{A o}_{2} \mathbf{S}$ & $98 \pm 0.5$ & $33 \pm 2$ & $23 \pm 3$ & $\mathrm{~S}$ \\
\hline
\end{tabular}

Baseline: before venom injection; HR: heart rate; MABP: mean arterial blood pressure; RR: respiratory rate; $\mathrm{Ao}_{2} \mathrm{~S}$ : arterial $\mathrm{O}_{2}$ saturation; $\mathrm{S}$ : significant: $\mathrm{NS}$ : not significant $(\mathrm{p}<0.05)$.

\section{DISCUSSION}

In the present study all the animals died within 3 to 3.5 hours after venom injection. The dose of injected venom was in accordance with the LD50 level $(4.5 \mathrm{mg} / \mathrm{kg})$ determined in mice. The LD50 dose of Me venom in mice appears to be the lethal dose in rabbits. This venom dose was selected because we wanted to see the acute effect of venom within a limited time.

Electrocardiographic changes such as infarct-like pattern and arrhythmia, induced by injecting $M e$ venom into rabbits, appeared to be the result of myocardial ischemia. Ismail et al. (16) reported myocardial damage and cardiac arrhythmia following scorpion envenomation in experimental animals and Gueron et al. (9) reported such manifestations in humans. ST elevation or depression in limb and precordial leads, and the inversion of $T$ and $Q$ waves configure an acute myocardial infarction-like pattern. These electrocardiographic abnormalities have been observed following scorpion envenomation $(1,17)$. This study showed myocytolysis, coagulation necrosis, focal hemorrhage and thrombus formation in myocardium and on endocardial surfaces as well as inflammation in the heart after Me venom in rabbits, The lungs showed alveolar edema, hemorrhage, vascular congestion thrombus and interstitial inflammation. Cardiac dysfunction, pulmonary edema and hemorrhage with inflammatory infiltrates in the heart and lung were previously described (18-20). Release of cholinergic and adrenergic neurotransmitters from sympathetic and parasympathetic nerve terminals after the binding of scorpion toxins to sodium channels of axonal membranes has been demonstrated (21). In addition, scorpion venoms may have a direct effect on cardiac muscle fibers while their toxins may also 
inactivate sodium channels of cardiac cells (22). Cardiac troponin T elevation in one rabbit coupled with LDH elevation in serum of all animals is one of the interesting results of this study. Although the average levels of troponin and LDH after venom injection increased by almost two fold, neither alteration was statistically significant. These variations may be explained by the different physiological response of each individual. Cardiac troponins, cardiac troponin $\mathrm{T}$ and cardiac troponin $\mathrm{C}$ comprise the gold standard for the detection of myocardial necrosis (23). Elevation of LDH in blood serum usually implies tissue injury (18). Although the ECG changes reveal myocardial damage in some of the envenomed rabbits, the important heart necrotic marker CK-MB did not show a significant elevation, perhaps due to the time required for serum elevation of this marker.

The other important finding was severe lung edema in all animals. Pulmonary edema is one of the most important complications following scorpion poisoning (18). A case report presented lung evidence compatible with adult respiratory distress syndrome and electron microscopic findings consistent with acute lung injury and increased alveolocapillary membrane permeability after Tityus serrulatus scorpion sting (24). Two factors can induce pulmonary edema: a cardiogenic factor due to dysfunction of the left ventricle and a non-cardiogenic factor related to inflammatory response (13, 14). In this study, 40-60 minutes after Me venom injection, all the rabbits showed signs resembling acute respiratory distress syndrome (ARDS). Animals presented decreases in respiratory rate, apnea, heavy open-mouth wheezing, bronchial secretions and severe decline in oxygen arterial saturation. This syndrome has been observed in ram lungs after Tityus discrepans scorpion envenomation (25). Additionally D'Suze et al. (26) suggested that scorpion venom respiratory distress syndrome (SVRDS) should be implicated in place of pulmonary edema. Although only one animal in the present study showed myocardial infarction, all the specimens showed severe alveolar edema and respiratory distress which indicates that the pulmonary changes due to Me venom are non-cardiogenic in origin. Thrombi observed in rabbit lungs could be explained by venom damage of vascular endothelial cells or by actions exerted on the coagulation system. The consequence of thrombosis depends on the site of vessel occlusion, and can result in death (27). Therefore, Me venom may be toxic to the vessel wall. Endothelial cells represent the first cellular barrier to blood-borne toxins that reach the deeper vessel wall layers. These cells are particularly susceptible to toxic insult. Toxins that reach the 
subendothelial space may cause injury to medial smooth muscle cells and/or adventitial fibroblasts (27). Hence, Me venom may cause injury to endothelial cells and/or medial smooth muscle cells and/or adventitial fibroblasts. Furthermore, Me venom produced direct inflammatory reaction in the lungs and heart. Tityus discrepans venom also produced inflammatory reaction in different tissues and fibrin deposition (25). Our finding also agrees with another study that found a highmolecular-weight (100 kDa) toxin (T3) which, having been isolated from Mesobuthus tamulus venom, exhibited toxicity in cardiopulmonary parameters. It was called "pulmonary edema-producing toxin (PoTx)" and was identified as the toxic principle for the manifestation of pulmonary edema seen after Mesobuthus tamulus envenomation (15).

In conclusion, the present data show that $M e$ venom injection in rabbits evoked severe pulmonary edema and death. Heart changes were also induced but can be excluded as the cause of death due to their lower severity and prevalence. Therefore, pulmonary damage following envenomation may result from a direct effect of $\mathrm{Me}$ venom on endothelial cells of pulmonary vessels, whereas pulmonary edema following $\mathrm{Me}$ envenomation is not cardiogenic in origin. Understanding the cardiopulmonary complications that follow Me envenomation could lead us to a better therapeutic strategy.

\section{REFERENCES}

1. Gueron M, Ilia R, Margulis G. Arthropod poisons and the cardiovascular system. Am J Emerg Med. 2000;18(6):708-14.

2. Radmanesh M. Androctonus crassicauda sting and its clinical study in Iran. J Trop Med Hyg. 1990;93(5):323-6.

3. Ozkan O, Carhan A. The neutralizing capacity of Androctonus crassicauda antivenom against Mesobuthus eupeus scorpion venom. Toxicon. 2008;52(2):375-9.

4. Bucaretchi F, Baracat E, Nogueira RN, Zambrone FAD. Severe scorpion envenomation in children: a comparison between Tityus bahiensis and Tityus serrulatus. Rev Inst Med Trop São Paulo. 1995;37(4):331-6.

5. Mota J, Ghersy de Nieto M, Bastardo M, Rodríguez J, Duque L, Freytez L. Emponzoñamiento escorpiónico, clínica y laboratorio usando antivenina. Bol Hosp Niños J M de los Ríos. 1994;30(3):35-40. 
6. Porras JL, Rosillo de González M, Girado Pastor M. Escorpionismo por Tityus discrepans: estudio retrospectivo 1983-1988. Arch Venez Pueric Pediatr. 1994;57(2):98-105.

7. Rossomando A, Rosillo M, Chacón de Gutiérrez E, Barra V, Moreno E, Albán AE. Pancreatitis aguda por emponzoñamiento escorpiónico: estudio prospectivo. GEN. 1997;51(4):259-62.

8. Sequera L, Sandoval L, Chávez A. Emponzoñamiento en niños por escorpión Tityus discrepans. Arch Venez Pueric Pediatr. 1993;56(1):44-7.

9. Gueron M, Ilia R, Sofer S. The cardiovascular system after scorpion envenomation: review. J Toxicol Clin Toxicol. 1992;30(2):245-58.

10. Sofer S, Gueron M, White RM, Lifshitz M, Apte RN. Interleukin-6 release following scorpion sting in children. Toxicon. 1996;34(3):285-338.

11. Rowan EG, Vatanpour H, Furman BL, Harvey AL, Tanir MO, Gopalakrishnakone P. The effects of Indian red scorpion Buthus tamulus venom in vivo and in vitro. Toxicon. 1992;30(10):1157-64.

12. Ozkan O, Kat I. Mesobuthus eupeus scorpionism in Sanliurfa region of Turkey. J Venom Anim Toxins incl Trop Dis. 2005;11(4):479-91.

13. Amaral CF, Rezende NA. Both cardiogenic and non-cardiogenic factors are involved in the pathogenesis of pulmonary oedema after scorpion envenoming. Toxicon. 1997;35(7):997-8.

14. Freire-Maia L, de Matos IM. Heparin or a PAF antagonist (BN-52021) prevents the acute pulmonary oedema induced by Tityus serrulatus scorpion venom in the rat. Toxicon. 1993;31(9):1207-10.

15. Deshpande SB, Alexa AB, Jagannadham MV, Rao GRK, Tiwari AK. Identification of a novel pulmonary oedema producing toxin from Indian red scorpion (Mesobuthus tamulus) venom. Toxicon. 2005;45(6):735-43.

16. Ismail M, Fatani AJ, Dabees TT. Experimental treatment protocols for scorpion envenomation: a review of common therapies and an effect of kallikrein-kinin inhibitors. Toxicon. 1992;30(10):1257-79.

17. Fatani AJ, Furman BL, Zeitlin IJ. The involvement of plasma kinins in the cardiovascular effects of Leiurus quinquestriatus scorpion venom in anaesthetised rabbits. Toxicon. 1998;36(3):523-36. 
18. Adi-Bessalem S, Hammoudi-Triki D, Laraba-Djebari F. Pathophysiological effects of Androctonus australis hector scorpion venom: tissue damages and inflammatory response. Exp Toxicol Pathol. 2008;60(4-5):373-80.

19. Daisley H, Alexander D, Pitt-Miller P. Acute myocarditis following Tityus trinitatis envenoming: morphological and pathophysiological characteristics. Toxicon. 1999;37(1):159-65.

20. Mazzei de Dàvila CA, Dàvila DF, Donis JH, de Bellabarba GA, Villarreal V, Barboza JS .Sympathetic nervous system activation, antivenin administration and cardiovascular manifestations of scorpion envenomation. Toxicon. 2002;40(9):133946.

21. Ismail M. The scorpion envenoming syndrome. Toxicon. 1995;33(7):825-58.

22. Teixeira AL, Fontoura BF, Freire-Maia L, Machado CR, Camargos ER, Teixeira MM. Evidence for a direct action of Tityus serrulatus scorpion venom on the cardiac muscle. Toxicon. 2001;39(5):703-9.

23. Collinson PO, Gaze DC. Biomarkers of cardiovascular damage and dysfunction: an overview. Heart Lung Circ. 2007;16(3):S71-S82.

24. Amaral CF, Barbosa AJ, Leite VH, Tafuri WL, de Rezende N. Scorpion stinginduced pulmonary oedema: evidence of increased alveolocapillary membrane permeability. Toxicon. 1994;32(8):999-1003.

25. D'Suze G, Salazar V, Díaz P, Sevcik C, Azpurua H, Bracho N. Histophatological changes and inflammatory response induced by Tityus discrepans scorpion venom in rams. Toxicon. 2004;44(8):851-60.

26. D'Suze G, Comellas A, Pesce, Sevcik C, Sanchez-de-León R. Tityus discrepans venom produces a respiratory distress syndrome in rabbits through an indirect mechanism. Toxicon. 1999;37(1):173-80.

27. Klaassen CD, Watkins III JB. Casarett \& Doull's essentials of toxicology. 3rd ed. New York: McGraw-Hill; 2003. p. 281-3. 